\title{
Characterization of intergranular stress corrosion cracking behavior of a FSW Al-Cu-Li 2050 nugget
}

\author{
M. Dhondt ${ }^{1, a}$, I. Aubert ${ }^{1}$, N. Saintier ${ }^{2}$ And J.M. Olive ${ }^{1}$ \\ 1 I2M, UMR 5295, Université de Bordeaux, CNRS, 351 Cours de la Libération, 33405 Talence, France \\ 2 I2M, UMR 5295, Arts et Métiers Paris-Tech (Centre de Bordeaux-Talence), Esplanade des Arts et Métiers, \\ 33405 Talence, France
}

Received 9 September 2013, Accepted 7 January 2015

\begin{abstract}
This study deals with the in service durability of an alloy Al-Cu-Li 2050 friction stir welded. In an aeronautical context, this material could be submitted to mechanical stresses and a corrosive environment. Thus, the aim of this study is to characterize the intergranular stress corrosion cracking (IGSCC) behavior of the 2050 FSW weld nugget. First, a link has been established between several microstructural heterogeneities induced by the welding process and local strain variations, then between these heterogeneities and the initiation and propagation of IGSCC cracks.
\end{abstract}

Key words: Aluminium alloy / friction stir welding / intergranular stress corrosion

\section{Introduction}

Friction stir welding (FSW) is a solid state metal joining technique for joining aluminum alloys, even those that are typically considered to be un-weldable, such as aluminum alloys 2XXX and 7XXX. Using both lightweight aluminum lithium alloy and FSW technique could decrease significantly the weight of aircraft structures. The FSW process generates strong microstructural changes due to the high plastic deformation and the frictional heat induced by the rotating tool. Friction stir welded joints consist of three zones involving specific microstructures [1-3] namely: heat affected zone (HAZ), thermomechanically affected (TMAZ) zone and weld nugget $(\mathrm{WN})$.

Some works showed that friction stir-welded joints of alloys AA2050, AA2024 and AA7050, exhibit susceptibility to localized corrosion compared to the base metal [2-4], and Bousquet [3] highlighted a transition between pitting corrosion in base metal of alloy 2050 and intergranular corrosion (IGC) in the weld nugget. For Al$\mathrm{Cu}-\mathrm{Li}$ alloys, the localized corrosion susceptibility can be correlated with the presence of precipitates $\mathrm{T} 1\left(\mathrm{Al}_{2} \mathrm{CuLi}\right)$, due to the potential difference between the precipitates and the matrix $[5,6]$. IGC has been found to be strongly dependent on the crystallographic nature of the grain boundaries $[7,8]$. But in the case of this study, not only

\footnotetext{
${ }^{a}$ Corresponding author:

matthieu.dhondt@ensta-bretagne.fr
}

grain boundary character distribution but also the mechanical fields play a key role. For 2024 aluminum alloys, applying an internal stress [10], or an external stress [9] causes an increase of the IGC growth rate.

The intergranular stress corrosion cracking (IGSCC) being strongly correlated with the microstructure and particularly precipitates, it can be improved by heat treatments after welding. Recently, Proton et al. [2] highlighted that a post-welding heat treatment improves the resistance to environmental degradation of 2050 FSW joints. In this study, we will focus on the post-welding heat-treated weld nugget of AA2050, which is the preferential IGSCC initiation zone of the friction stir-welded joint. The effects of microstructure heterogeneities on local mechanical fields and their consequences on the IGSCC behavior have been investigated.

\section{Material and methods}

The weld nugget used in this study, comes from the friction stir welding of two $15 \mathrm{~mm}$ thick sheets of AA2050 T3 (solutionising, quenching and stretching), followed by a post-welding heat treatment at $155^{\circ} \mathrm{C}$ during $30 \mathrm{~h}$. Tensile samples were machined in the middle of the nugget, along the welding direction (Fig. 1).

To establish a correlation between crystallographic texture and local strain heterogeneities, EBSD maps of about $1500 \times 400 \mu \mathrm{m}$ with a step of $2 \mu \mathrm{m}$ were performed using a OIM EBSD system on a ZEISS EVO50 scanning 

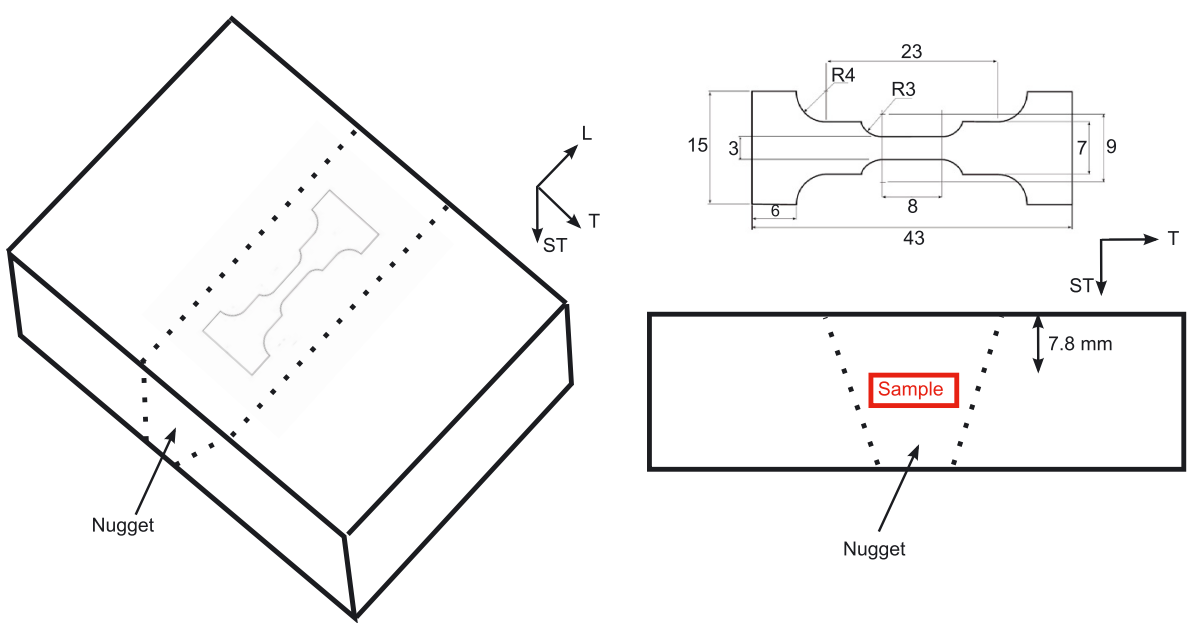

Fig. 1. Tensile samples machining.

electron microscopy (SEM) along the gauge length of samples previously mechanically polished to a mirror finish $(1 / 4 \mu \mathrm{m}$ OP-S solution). Then, the samples were electrolytically etched in a $\mathrm{HBF}_{4}$ solution with an intensity of $0.2 \mathrm{~A} . \mathrm{cm}^{-2}$ during $2 \mathrm{~min}$, to create a texture used to measure displacement fields by Digital Images Correlation (DIC) during the tensile test. In-situ tensile tests in air were performed at $\dot{\epsilon}=5 \times 10^{-5} \mathrm{~s}^{-1}$ total strain rate under a digital microscope KEYENCE VHX-1000E. A strain gauge provided the strain in the range of 0 to $2 \%$. Above $2 \%$, the strain was estimated thanks to LVDT displacements measurements. The local strain fields were estimated by DIC using the software Correli ${ }^{Q 4}$, from 300 optical images taken every $15 \mathrm{~s}$ (for a $\Delta \epsilon=7.5 \times 10^{-4}$ ) during the tensile test. The investigated area for DIC measurements of about $1600 \times 1200 \mu \mathrm{m}$ contained the EBSD map zone. In addition, some corrosion tests were performed to link the IGSCC cracks initiation with the microstructural heterogeneities and the mechanical fields. The corrosion tests were performed on samples mechanically polished to a mirror finish (1 $\mu \mathrm{m}$ diamond paste). All the corrosion tests were performed in a $1.0 \mathrm{M} \mathrm{NaCl}$ aerated solution at open current potential and at room temperature (immersion duration 1h30). In order to study the effect of internal and external stress on IGSCC, three types of tests were conducted:

- corrosion tests (COR) by immersion in $\mathrm{NaCl}$;

- stress corrosion cracking tests (SCC) by application of an external loading during immersion in $\mathrm{NaCl}$;

- corrosion tests by immersion in $\mathrm{NaCl}$ of samples previously pre-strained in air (PRE) to show the influence of residual stresses.

To clearly evaluate the external stress effect on corrosion behavior, corrosion tests were performed on the samples previously submitted to SCC tests, by immersion of the heads of the tensile samples. SCC tests were conducted at $\dot{\epsilon}=2 \times 10^{-6} \mathrm{~s}^{-1}$ strain rate. The corrosive solution was added at a stress higher than the yield stress in order to limit the pitting phenomenon. SCC tests were performed up to $1 \%$ plastic strain (immersion duration 1h30). For corrosion tests on pre-strained samples, a tensile test in air was performed at $\dot{\epsilon}=5 \times 10^{-5} \mathrm{~s}^{-1}$ up to $10 \%$ of plastic strain before immersion in $\mathrm{NaCl}$ solution. After the tests, the SCC cracks were observed using an optical microscope OLYMPUS PMG3 and a scanning electron microscope (SEM) JEOL 840A. After the SCC tests, the samples were mechanically polished with an OP-S solution $(1 / 4 \mu \mathrm{m})$, and EBSD maps were performed to highlight a correlation between IGSCC-cracks and the microstructure.

\section{Results}

\subsection{Relationship between microstructure and local strain heterogeneities}

Tensile tests performed on the weld nugget samples allow underlining significant strain heterogeneities as shown on the optical image shown in Figure 2a. In this image, dark bands can be observed due to the variation of roughness after tensile test. To quantify those local strain heterogeneities, DIC measurements were performed from the in-situ optical images taken during the tensile test. The map corresponding to local total strain in the tensile direction $\epsilon_{T T}$ at the specimen surface after $7 \%$ of global strain is shown in Figure 2b. Strain heterogeneities follow the dark bands observed on the optical image, the relative variation is about $15 \%$ between the maximum and the minimum $\epsilon_{T T}$ strain at the surface. The EBSD map previously carried out in the same zone is also shown and allows highlighting periodic crystallographic texture variations. The characteristic average band width formed by this texture was measured to be approximately $500 \mu \mathrm{m}$, which corresponds to the FSW tool advance per revolution. This microstructure corresponds to the typical "onion rings" structure of the FSW weld nugget [11]. By comparing to EBSD and DIC measurements, a good correlation is established between the strain heterogeneities and the crystallographic texture variation. "Onion rings" microstructure is mainly responsible for the strain heterogeneities of this material. 


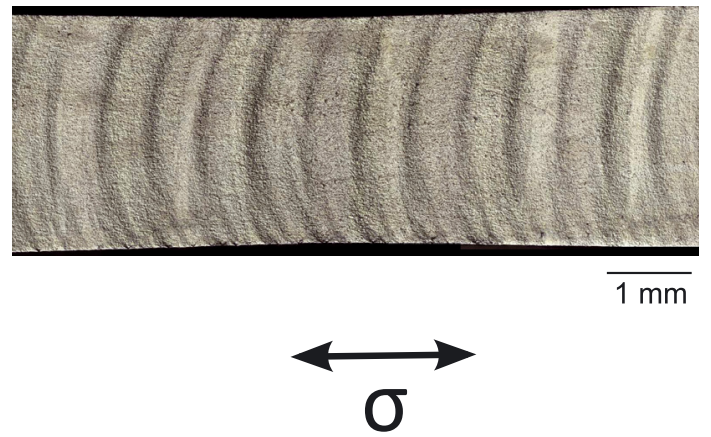

(a)

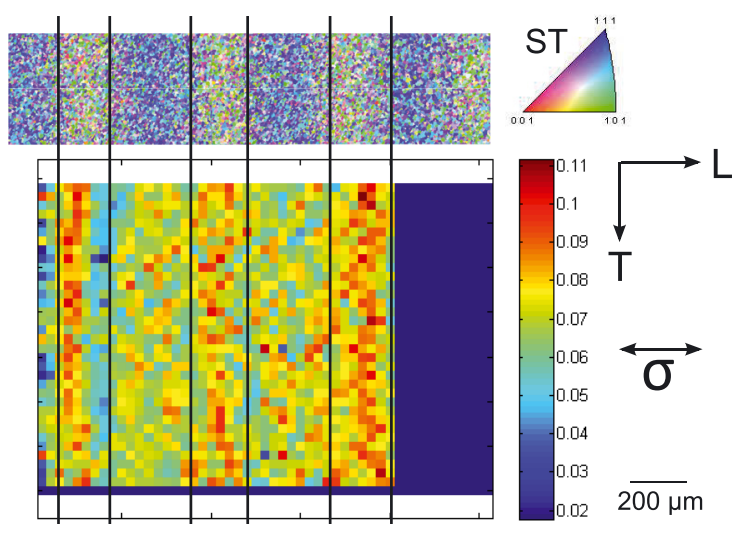

(b)

Fig. 2. Local strain heterogeneities: optical image and DIC measurements after $7 \%$ of global strain. (a) Optical image after tensile test. (b) Correlation between DIC measurements and EBSD maps.

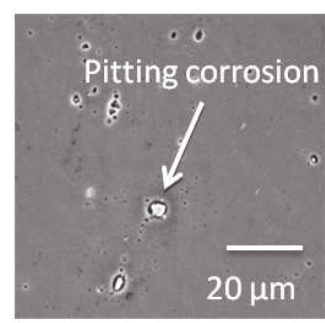

(a) $\mathrm{COR}$

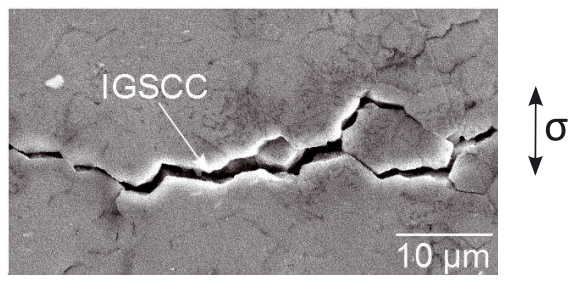

(b) SCC

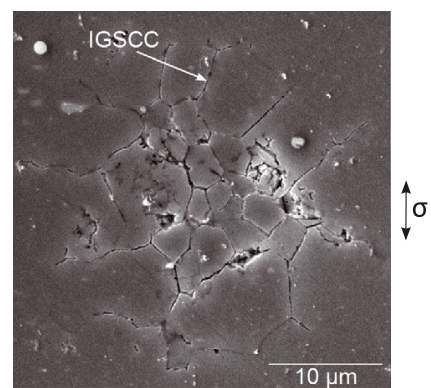

(c) PRE

Fig. 3. SEM images taken after (a) a corrosion test; (b) a SCC test; (c) a corrosion test on a pre-strained sample.

\subsection{Intergranular stress corrosion cracking (IGSCC)}

\subsubsection{Stress effect}

For each corrosion test, a SEM image characterizing corrosion features of the material is shown in Figure 3. Those pictures show that the weld nugget is sensitive to pitting corrosion when it is not submitted to a mechanical loading (Fig. 3a). A mechanical loading induces a change in corrosion features, damage by IGSCC becomes predominant even if pitting corrosion is still present (Figs. $3 \mathrm{~b}$ and $3 \mathrm{c}$ ). The same type of phenomenon was observed by Connolly and Scully [12] for alloy Al-Li-Cu 2096. Those observations clearly underline the fact that an internal or external stress is required to produce initiation of IGSCC for the experimental conditions investigated here (immersion duration, solution, temperature...).

The IGSCC features also depend on the nature (external or internal) of the applied stress. For SCC tests, cracks mainly propagate perpendicularly to the tensile direction (Fig. 3b). For corrosion tests on pre-strained samples, no macroscopic stress is applied, but plastic strain induced by the mechanical loading performed before immersion generates residual local stresses (due to intergranular strain incompatibilities). In this case, the development of IGSCC cracks is isotropic, no preferential propagation direction is observed as shown in Figure 3c.

In what follows, the study will focus on the SCC tests which correspond to the most critical situation. SEM observations reveal initiation of several cracks whose lengths and locations are distributed. A statistical analysis of the area shown in Figure 4a highlights that the crack density is about 168 cracks per $\mathrm{mm}^{2}$. The crack lengths distribution is shown in Figure $4 \mathrm{~b}$ and the crack length average is $20 \mu \mathrm{m}$. In this figure, the length of more than $50 \%$ of the cracks is lower than $10 \mu \mathrm{m}$. However, the length of a slight fraction $(\sim 2 \%)$ of them is higher than $100 \mu \mathrm{m}$. It can be observed on the optical image (Fig. 4a), that the cracks spacing along the stress direction show some degrees of periodicity. The correlation with microstructure is investigated in the next section.

\subsubsection{Microstructure effect at mesoscopic scale}

To establish a possible relationship between periodic texture variation and IGSCC initiation, EBSD maps were performed next to the largest intergranular cracks shown 


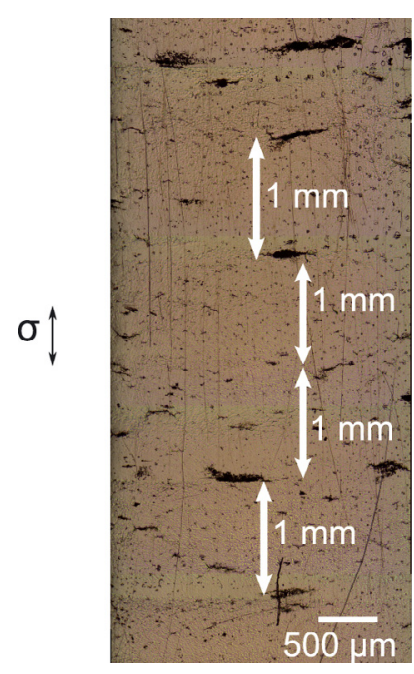

(a)

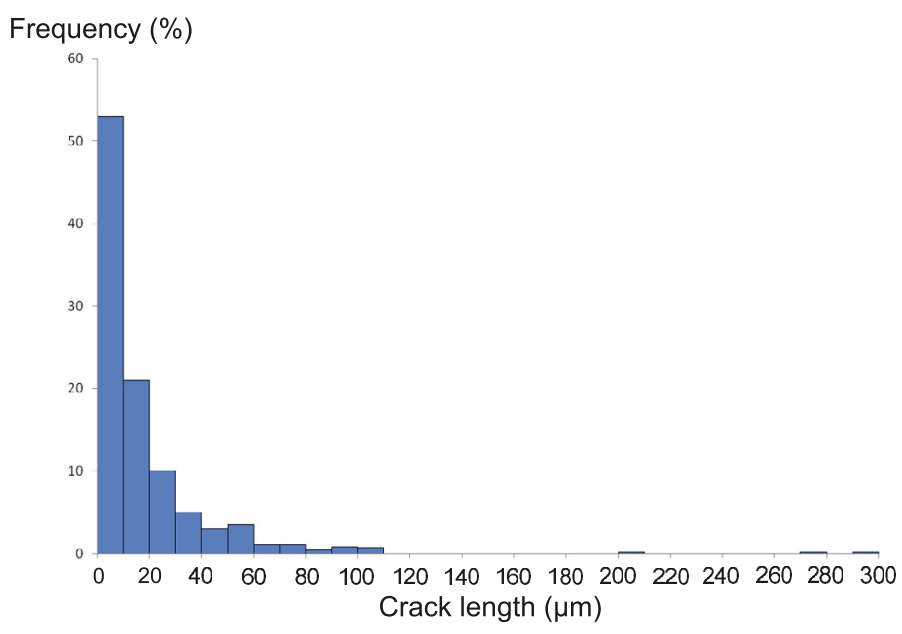

(b)

Fig. 4. Optical image and crack length distribution after IGSCC test. (a) Optical image of a sample submitted to an IGSCC test. (b) Crack length distribution in the sample.

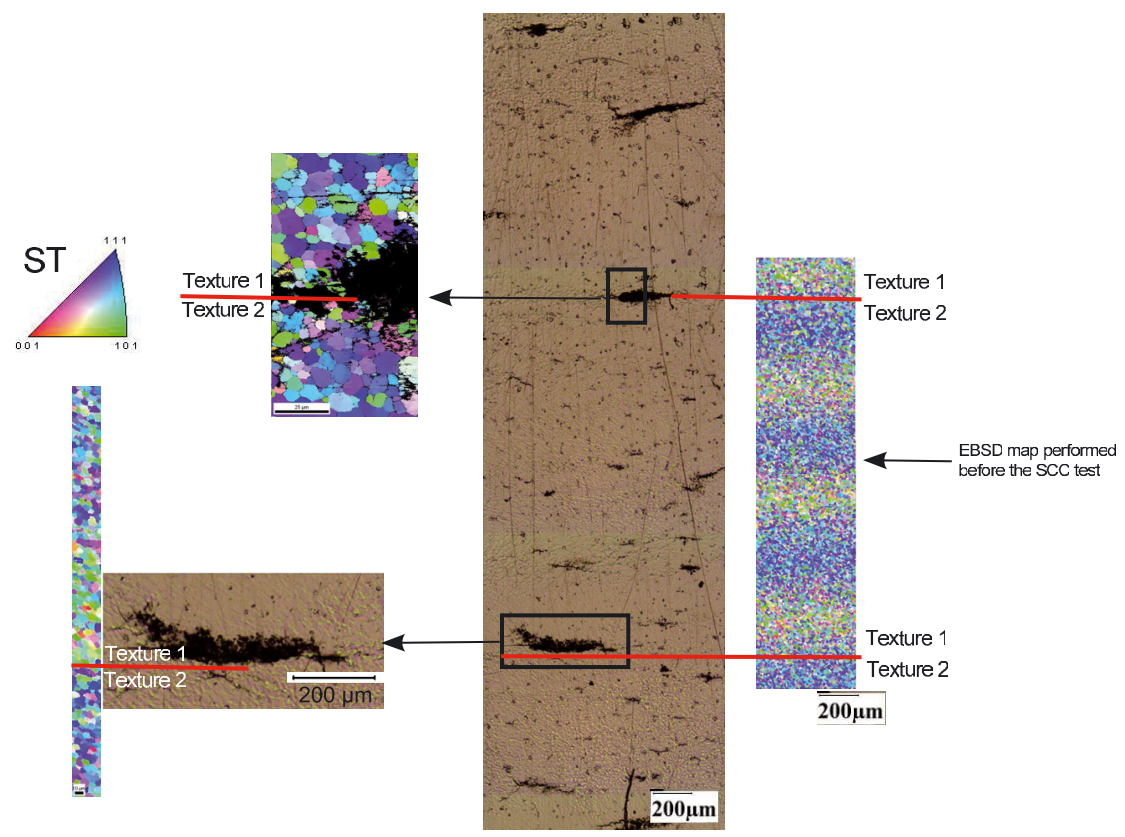

Fig. 5. Optical image of a sample submitted to IGSCC test and EBSD maps performed before and after the test next to the cracks.

in Figure 4a. Figure 5 shows the optic image and EBSD maps performed before and after the SCC tests. This figure clearly shows that those cracks initiate at texture bands boundaries. Strain incompatibilities generated by the co-existence of different crystallographic textures create some preferential sites for IGSCC initiation. However, texture variation is not the only parameter influencing IGSCC and smaller intragranular cracks uniformly initiate on the whole sample. Crack initiation can also depend on local mechanical fields and local microstructure (precipitation, grain boundary misorientations...). On the other hand, the frequency of the largest crack is two times lower than the texture band periodicity. It can be assumed that IGSCC initiation causes a stress relaxation in the crack plane, which reduces the initiation probability at the neighboring texture band.

\section{Conclusions}

Under severe experimental coupled environmental and mechanical conditions, IGSCC initiates, without pitting, at grain boundaries of 2050 FSW weld nugget. The initiation stage is shown to be strongly dependent on mechanical and microstructural parameters at the mesoscopic scale. At this scale, a periodical variation of the 
grains crystallographic orientations and associated strain heterogeneities were identified experimentally by combining EBSD and digital image correlation. It is shown that stress corrosion cracks initiate and propagate preferentially along the boundaries between textured bands. At the macroscopic scale, under stress corrosion cracking conditions, the multi-cracking process occurs and leads to the degradation of the material. Without any residual stress or macroscopic applied stress, a slight degradation in the form of pitting corrosion develops without any intergranular corrosion.

Acknowledgements. This work was financially supported by the ANR MatetPro program ANR-08-MAPR-0020-05 (Coralis project, Corrosion of Aluminium Lithium Structures).

\section{References}

[1] G. Pouget, A.P. Reynolds, Residual stress and microstructure effects on fatigue crack growth in AA2050 friction stir welds, Int. J. Fatigue 30 (2008) 463-472

[2] V. Proton, J. Alexis, E. Andrieu, C. Blanc, J. Delfosse, L. Lacroix, G. Odemer, Influence of post-welding heat treatment on the corrosion behavior of a 2050-T3 aluminum-copper-lithium alloy friction stir welding joint, J. Electrochem. Soc. 158 (2011) C139-C147

[3] E. Bousquet, Durabilité des assemblages soudés par friction stir welding (FSW), Corrélation entre microstructure et sensibilité à la corrosion, Ph.D. thesis, Université Bordeaux 1, 2011
[4] J.B. Lumsden, M.W. Mahoney, C.G. Rhodes, G.A. Pollock, Corrosion behavior of friction-stir-welded AA7050-T7651, Corrosion 59 (2003) 212-219

[5] R.G. Buchheit Jr., J.P. Moran, G.E. Stoner, Localized corrosion behavior of alloy 2090, The role of microstructural heterogeneity, Corrosion 46 (1990) 610-617

[6] J.F. Li, C.X. Li, Z.W. Peng, W.J. Chen, Z.Q. Zheng, Corrosion mechanism associated with $\mathrm{T} 1$ and $\mathrm{T} 2$ precipitates of $\mathrm{Al}-\mathrm{Cu}-\mathrm{Li}$ alloys in $\mathrm{NaCl}$ solution, J. Alloys Compd. 460 (2008) 688-693

[7] S.H. Kim, U. Erb, K.T. Aust, G. Palumbo, Grain boundary character distribution and intergranular corrosion behavior in high purity aluminum, Scripta Mater. 44 (2001) 835-839

[8] M.A. Arafin, J.A. Szpunar, A new understanding of intergranular stress corrosion cracking resistance of pipeline steel through grain boundary character and crystallographic texture studies, Corros. Sci. 51 (2009) 119-128

[9] N. Pauze, Fatigue de corrosion dans le sens travers court de tôles d'aluminium 2024-T351 présentant des défauts de corrosion localisée, Ph.D. thesis, École Nationale Supérieure des Mines de Saint-Étienne, 2008

[10] X. Liu, G.S. Frankel, B. Zoofan, S.I. Rokhlin, Effect of applied tensile stress on intergranular corrosion of AA2024T3, Corros. Sci. 46 (2004) 405-425

[11] R.W. Fonda, J.F. Bingert, Texture variations in an aluminum friction stir weld, Scripta Mater. 57 (2007) 10521055

[12] B.J. Connolly, J.R. Scully, Transition from localized corrosion to stress corrosion cracking in an Al- $\mathrm{Li}-\mathrm{Cu}-\mathrm{Ag}$ alloy, Corrosion 61 (2005) 1145-1166 